\title{
A formação em terapia ocupacional: entre o ideal e o real
}

\author{
The formation in occupational therapy: between the ideal and \\ the real
}

\section{Teresinha Cid Constantinidis ${ }^{1}$, Alexandre Cardoso da Cunha ${ }^{2}$}

http://dx.doi.org/10.11606/issn.2238-6149.v24i2p149-154

Constantinidis TC, Cunha AC. A formação em terapia ocupacional entre o ideal e o real. Rev. Ter. Ocup. Univ. São Paulo, v. 24, n. 2, p. 149-54, maio-ago. 2013.

RESUMO: Este estudo teórico visa discutir o processo de idealização da profissão, pelos alunos da Universidade Federal do Espírito Santo, em confronto com a realidade das experiências práticas, relacionando essa questão ao processo de formação do terapeuta ocupacional. Para tal discussão foram utilizados, como referência, estudos que abordam a identidade e formação em Terapia Ocupacional, a teoria de transversalidade e de produção de subjetividade. Indica que a idealização da Terapia Ocupacional, a forma como será construída no processo de formação, pode ser determinante da qualidade das ações na realidade dos atendimentos. Propõe pensar a formação como um espaço aberto, multivetorial, que possa produzir diferenciações, experimentações, afirmar modos de existência singulares, ressaltando a importância da relação professor-aluno nesse processo.

DESCRITORES: Terapia ocupacional; Prática profissional; Educação em saúde.
Constantinidis TC, Cunha AC. The formation in occupational therapy: between the ideal and the real. Rev. Ter. Ocup. Univ. São Paulo, v. 24, n. 2, p. 149-54, maio-ago. 2013.

\begin{abstract}
This theoretical study aims at discussing the process of idealization of the profession, by students of the Federal University of Espírito Santo, in confrontation with the reality of practical experiences, relating this question with the formation of the occupational therapist. For this discussion were used as reference studies on the identity and training in Occupational Therapy, transversality theory and production of subjectivity. Indicates that the idealization of Occupational Therapy, how will be built in the training process, can be determinant of the quality of the actions in the reality of care. It proposes to consider training as an open space, multivector, which can produce differentiations, trials, state natural modes of existence, emphasizing the importance of the teacher-student relationship in the process.
\end{abstract}

KEYWORDS: Occupational therapy; Professional practice; Health educatio

\footnotetext{
1. Universidade Federal do Espírito Santo - UFES.

2. Universidade Federal do Espírito Santo - UFES.

Endereço para correspondência: Teresinha Cid Constantinidis: R. Moacir Avidos, n. 156/1102, Vitoria ES, teracidc@uol.com.br
} 


\section{INTRODUÇÃO}

proposta deste estudo surgiu de reflexões a
partir da experiência de docência no curso
de graduação em Terapia Ocupacional da Universidade Federal do Espírito Santo (UFES).

A contratação dos primeiros terapeutas ocupacionais no Espírito Santo ocorreu no início na década de 1980, em centro de reabilitação e, mais tarde, na década de 1990, em hospital psiquiátrico. Somente a partir de 2000, com a consolidação das metas do SUS no Estado, houve maior divulgação da profissão, aumento do número de profissionais e ampliação do mercado de trabalho que, até então, era restrito às instituições citadas.

O fato de a profissão ter história muito recente no Estado parece colaborar para a falta de conhecimento e pouca informação sobre a Terapia Ocupacional por parte de alunos ingressantes no curso da UFES, única universidade a oferecer esse curso no Espírito Santo, desde 2009. No decorrer da graduação, no entanto, grande parte desses estudantes torna-se engajada na defesa e luta pelo reconhecimento e divulgação da Terapia ocupacional, muitas vezes, estabelecendo relação apaixonada com a futura profissão. Paixão e idealização têm um vínculo, mesmo que temporário ${ }^{1}$ e é comum ouvir desses estudantes: "A Terapia Ocupacional é linda".

Ao longo do curso, os alunos participam de atividades práticas de observação e atendimentos em serviços de saúde, em serviços de assistência social, em escolas e em instituições filantrópicas, tanto em disciplinas curriculares como em projetos de extensão e pesquisa. No entanto, em momento de estágio curricular - nos dois últimos períodos do curso, perfazendo carga horária de 30 horas semanais -, expressam certa decepção em relação às práticas desenvolvidas por terapeutas ocupacionais, preceptores com quem compartilham o campo de trabalho. Nas supervisões semanais, realizadas por professores do curso - entre eles, autores deste estudo - são frequentes reclamações sobre a atuação desses terapeutas ocupacionais. $\mathrm{Na}$ avaliação desses alunos, as práticas estão aquém das demandas colocadas à Terapia ocupacional e as possibilidades de atuação são reduzidas em relação às demandas da população. Nessas situações, a frase "a Terapia Ocupacional é linda, os terapeutas ocupacionais são feios" é dita com freqüência. Explicam que a Terapia Ocupacional linda é aquela aprendida em sala de aula, nos livros, nos trabalhos científicos e os terapeutas ocupacionais ("feios") não levam adiante, em suas práticas, o que se espera da profissão.

Acredita-se que a questão vá além da falta de competência desses profissionais e que está relacionada ao processo desses estudantes ao trazer, para a realidade concreta dos serviços, uma Terapia Ocupacional idealizada, havendo conflito no confronto entre a teoria - ligada às condições ideais-, com o campo real - parte das dinâmicas institucionais, da variedade de necessidades e demandas da população- que necessita ser acolhido.

A partir daí, este estudo visa discutir o processo de idealização da profissão, pelos alunos citados, em confronto com a realidade das experiências práticas, relacionando essa questão ao processo de formação do terapeuta ocupacional.

Para tal discussão foram utilizados, como referência, estudos que abordam a identidade e formação em Terapia Ocupacional, a teoria de transversalidade e de produção de subjetividade. Como resultado do caminho do desenvolvimento da discussão, o estudo foi estruturado em seis tópicos que contemplam fatores inerentes ao campo de atuação da profissão, o contexto dos alunos da UFES no processo de escolha e idealização profissional, a abordagem da realidade nas experiências práticas, assim como o modelo de formação de profissionais de saúde e o desafio de preparar os alunos de Terapia Ocupacional para lidarem com condições reais que estão presentes no dia a dia dos serviços.

\section{TERAPIA OCUPACIONAL: A ESCOLHA}

$\mathrm{Na}$ experiência de ensino na graduação é possível identificar que os alunos ingressam em seus cursos trazendo noções idealizadas do que é ser profissional, que podem ser associadas à imagem que a sociedade tem da profissão e do seu trabalho ${ }^{2}$.

$\mathrm{Na}$ Terapia Ocupacional alguns fatores inerentes à profissão podem dificultar seu conhecimento/ reconhecimento social. O fato de ter seu campo de atuação constituído em um espaço de multiplicidades discursivas e práticas marcadas por inúmeras possibilidades e diversidade de atuação ${ }^{3}$, pode ser um desses fatores. Neste sentido, em meio à transformação do modelo de atenção à saúde, com a superação do paradigma do modelo biomédico, centrado em procedimentos, a Terapia Ocupacional, como outras profissões da saúde, tem a diluição da especificidade de sua prática e campo de atuação. Além disso, a falta de um repertório comum, resultado da falta de sistematização de conhecimentos das ações e da produção cientifica da profissão ${ }^{4}$, seria outro fator a ser considerado.

Somado a isso, no Espírito Santo, a Terapia Ocupacional é ainda uma profissão nova, com o campo profissional em construção, o que pode colaborar para que o aluno ingresse no curso sem ter clara a noção do trabalho 
do terapeuta ocupacional ${ }^{5,6}$.

Traverso-Yépez e Morais apontam que a motivação dos alunos na escolha do curso está relacionada à identificação/interesse com as atividades de cada profissão e com o desejo de realização profissional/ pessoal, especialmente em função do contato com as práticas de profissionais significativos na vida deles. Essa premissa seria válida para os alunos de Terapia Ocupacional da UFES?

$\mathrm{Na}$ UFES, pesquisa com alunos de primeiro e segundo períodos do curso de Terapia Ocupacional aponta que uma das motivações para essa escolha seria o campo de atuação em saúde. Muitos desses alunos fizeram tentativas fracassadas em ingressar em outros cursos, ou chegaram a cursar outras graduações da área, mas, por razões diversas, desistiram. Outra motivação estaria relacionada ao ingresso em universidade pública, já que o curso de Terapia Ocupacional na UFES é um dos menos concorridos da universidade e, estando matriculados, seria um caminho fácil para transferência de curso. Assim, grande parte desses alunos não teria, inicialmente, interesse específico na profissão e nem mesmo na forma de atuação do terapeuta ocupacional e a escolha não seria influenciada pela idealização ou por identificação profissional ${ }^{5}$.

No entanto, são alunos dessa mesma universidade, do mesmo curso em que foi realizada a pesquisa citada, que apresentam conflito entre a idealização da profissão e a realidade profissional. Assim, infere-se que a idealização profissional aconteceu durante a formação.

Baccaro e Shinyashik ${ }^{7}$ apontam que a formação profissional implica o processo de socialização da profissão e desenvolve um sentimento de identidade profissional típico dos membros de sua área. Este processo envolve a aproximação da cultura profissional, ou seja, internalização de regras e valores do grupo, fazendo com que o indivíduo sinta-se identificado com a profissão. Identidade em uma conotação dinâmica, em construção realizada pelos sujeitos em relação social. Nesse processo, o aluno entra em contato com um campo de saberes já estruturado que deverá interiorizar, mas que será transformado na relação ativa com o processo de trabalho, havendo a sujeição do real ao que é idealizado e a transformação do ideal em face às exigências do real

\section{A REALIDADE PROFISSIONAL, A TEORIA E A PRÁTICA}

No acompanhamento desses alunos, entende-se que, na forma de olhar a realidade, quebram a unidade entre teoria e prática ou colocam uma em reboque da outra. Essa reação é esperada nas primeiras experiências práticas, porém correse o risco da estagnação neste processo, o que pode resultar em cristalização de dicotomias ou polarização maniqueísta como apresentada pelos alunos: "terapia ocupacional linda" - inalcançável, pois ideal - ou "feia" - uma realidade sobre a qual o aluno tem dificuldades em atuar.

Para $\operatorname{Ramos}^{8}$, se a teoria fica simplesmente a reboque da prática, os fenômenos assumem seu desenvolvimento causal sem que se possa neles intervir. Neste caso, a teoria se tornaria exclusivamente constatação e confirmação dos fatos e não poderia cumprir uma função prática. Desse modo, a Terapia Ocupacional apreendida teoricamente e ocupando somente um lugar idealizado, se tornaria "linda", intocável, frente à realidade "feia".

Mesmo reconhecendo certa autonomia dos contextos teóricos e práticos, o trabalho com os alunos, nessas supervisões, converge no sentido de discutir a articulação entre o que é idealizado na construção teórica e sua função na prática. Busca-se superar a representação da prática como campo exclusivo de aplicação ou verificação de idéias, propostas ou modelos. Esta articulação traz uma dinâmica, um movimento circular em que a investigação parte dos fatos, do contexto, e a eles retorna após um processo de apropriação teórica.

\section{O IDEAL E O REAL NA FORMAÇÃO}

Em 2002 foram implantadas as Diretrizes Curriculares Nacionais (DCN) para os cursos de Terapia Ocupacional, em consonância com a necessidade de mudança no modelo de formação dos profissionais de saúde, na perspectiva da formação de um profissional generalista, reflexivo e comprometido com os princípios da universalidade, equidade e integralidade, referentes ao Sistema Único de Saúde (SUS). A partir daí, os cursos devem adequar seus currículos buscando superar a lógica mercantilista e curativa, centrada em procedimentos, preparar o futuro profissional para atuação em diferentes níveis de atenção, com ações de promoção e reabilitação a serem realizadas prioritariamente em território delimitado, o mais próximo possível do espaço de vida das pessoas 9 .

De forma geral, a elaboração de novos currículos - conforme trabalhos apresentados em 2012 no XII Encontro Nacional de Docentes de Terapia ocupacional e II Seminário Nacional de Pesquisa em Terapia Ocupacional - tem a integração ensino-serviço como fundamento para a construção do papel do terapeuta ocupacional, em conformidade com as DCN do curso ${ }^{10-13}$. No entanto, a problematização das bases de uma prática que vise à construção de um SUS real, que aponte para uma formação 
profissional condizente com as novas demandas e exigências, ainda permanece em pauta nas discussões entre pesquisadores, docentes, profissionais e estudantes de Terapia Ocupacional ${ }^{14}$.

Neste sentido, infere-se que o desafio na formação do profissional da saúde - no caso, do terapeuta ocupacional - é preparar o aluno para equacionar a relação entre as condições ideais e reais que estão presentes no dia a dia dos serviços, nos investimentos para transformação das realidades no atendimento às necessidades da população.

Assim, a formação consistiria no diálogo entre o ideal e o real visando alcançar o possível nas ações; resultaria de um processo de transformação que se dá entre a realidade considerada e o modelo idealizado. A realidade que se tem acesso no território existencial de cada um, na relação professor-aluno, na relação terapeuta ocupacionalpopulação atendida-instituições e o ideal que vai sendo construído nessas relações, que trazem as possibilidades e limites que vão transformando a realidade.

\section{O PROFESSOR E O SEU IDEAL}

Quais seriam as conseqüências no processo de formação, se também o professor se fechasse em um modelo ideal de Terapia Ocupacional?

Se isso ocorre, parte-se da premissa que esse tipo de idealização por parte do professor, segundo um modelo de terapia ocupacional transcendente abordado por meio de verdades absolutas, será reproduzida na relação com o aluno e no processo de formação.

Na relação professor-aluno, estabelecer ligações, sem impor uma determinada "verdade", é o aspecto mais delicado da tarefa docente ${ }^{15}$. O professor pode colocar em prática, mesmo que involuntariamente, a imposição de modelos ideais em uma hierarquia de saberes em relação aos alunos, valores transcendentes a essa relação, dandose interações e intervenções baseadas em valores morais e estabelecidas de forma verticalizada, que seriam referências no processo de ensino.

Dessa forma, na questão colocada, o resultado seria uma formação homogeneizada, formatando os alunos de acordo com o ideal de Terapia Ocupacional do professor. O encontro entre aluno e professor, nessa relação que aí se estabelece, pode levar a sentimentos de frustração em ambos os atores: o primeiro por não conseguir colocar em prática o modelo do professor e o segundo que se frustra por não ver concretizado seu ideal de terapeuta ocupacional no aluno.

Para Spinosa ${ }^{16}$, encontro é a capacidade de afetarmos e de sermos afetados por outros seres. O bom encontro se dá quando há aumento de potência de agir de cada um dos atores da relação, resultando em alegria, podendo haver união de forças, aumentando as possibilidades de ação desses sujeitos. No Tratado Político de 1994, Spinosa ${ }^{17}$ afirma: "Se duas pessoas concordam entre si e unem suas forças, terão maior poder conjuntamente e, conseqüentemente, um direito sobre a Natureza que cada uma delas não possui sozinha" (p.35). O mau encontro, por sua vez, há diminuição da potência de agir, quando um corpo decompõe o outro corpo, levando à tristeza.

Segundo a ótica espinosana pode-se afirmar que o encontro entre professores e alunos, segundo as condições colocadas, pode gerar tristeza e sentimento de impotência em ambos os atores da relação.

Por isso, aponta-se a importância da reflexão da relação professor-aluno, no sentido de colaborar na potencialização de futuros profissionais e seus professores. Para isso é necessário que o professor reflita sua prática, os valores acadêmicos disciplinares, e se aproxime da realidade desses alunos, na afirmação de suas potências singulares para que se possa gerar composição de forças. É preciso "dar lugar para a alegria da especulação e experimentação, base do afetar/ser afetado que aumenta a potência de agir/ criar/afirmar advinda da maior composição dos encontros"18.

É importante que as vivências, experiências dos alunos possibilitem a saída de lugares comuns, universais. Para isso é necessário construir com o aluno o aporte para ações, reflexões e formas de lidar singulares, de acordo com as possibilidades e limites da realidade da população atendida pela Terapia Ocupacional.

Poder acompanhar o aluno na formação é colocarse junto no processo de transformação que se dá entre a realidade considerada e o modelo idealizado.

\section{OS ENVOLVIDOS NA FORMAÇÃO: FORMADOR E FORMANDO}

Passos ${ }^{19}$, apoiado no conceito de transversalidade de Guattari ${ }^{20}$ (2004) considera que o processo de formação acolhe por um lado um formando, sujeito com sua história, suas formas, verdades e memória e, por outro, um processo de subjetivação que se opõe a um perfil imutável, que traça uma dinâmica que varia de acordo com as inúmeras combinações de forças e fluxos, por processos individuais, coletivos e sociais que o atravessam. Neste caso, a forma definitiva, o sujeito modelo - em seu estado já constituído, com significados universais, pré-estabelecidos, da forma dele se conduzir - é apenas um ideal a ser alcançado, não possuindo uma realidade definitiva ou acabada.

Segundo Guattari ${ }^{20}$, a transversalidade se constitui 
como meio de escapar à verticalidade hierárquica dos organogramas piramidais das instituições, dos estabelecimentos e da horizontalidade massificante que estabelece agrupamentos homogêneos de indivíduos e saberes baseados em características comuns. $\mathrm{O}$ autor conceitua a transversalidade como atravessamento mútuo de campos de saberes que se interpenetram, se misturam a partir de suas peculiaridades, suas características próprias, conservando-as e, sobretudo, ampliando-as. A transversalidade tende a se realizar quando ocorre uma comunicação máxima entre os diferentes níveis e sentidos de saberes.

Trazendo esse conceito para a discussão da formação profissional, no encontro professor-aluno, a formação se daria na intercessão desses saberes, tomando novos percursos ao sair dos saberes constituídos, produzindo novas articulações em diferentes campos ${ }^{19}$. Dessa forma, o profissional de terapia ocupacional se constituiria no processo de produção de subjetividades imanente da relação professor- aluno, na transformação desses atores para além de uma forma fixa pré-existente, acontecendo um devir. Passos $^{19}$ aponta que a transversalização se realiza na zona de vizinhança de processos de subjetivação do formador e do formando. Nesse processo de formação, que aposta nos devires sempre presentes, a dissolução dos sujeitos dessa relação é considerada.

Devir não é atingir uma forma (identificação, imitação, mimese), mas encontrar a zona de vizinhança, de indiscernibilidade ou de indiferenciação tal que já não seja possível distinguir-se de uma mulher, de um animal ou de uma molécula: não imprecisos nem gerais, mas imprevistos, não-preexistentes, tanto menos determinados numa forma quanto se singularizam numa população $0^{21}(\mathrm{p} .11)$.

Assim, o devir terapeuta ocupacional para o formando opera um devir outra coisa do formador, em uma relação em que ambos aprendem: "Aprender é potência de devir"22 (p.18).

A transversalidade é uma zona de abertura e fortalecimento da diferença. Assim, a dificuldade na relação acontece quando não há transversalidade, quando diante da diferença entre os valores, pensamentos e ações do formador e do formando, o primeiro reage despotencializando o segundo, por se tratar de uma realidade diferente de seus supostos modelos, tentando encaixar, nos registros de seus referenciais, todo o processo da ordem da criação, da ruptura e do novo trazido pelo aluno. No entanto, estando o formador aberto a fluxos criativos, não havendo uma imagem definitiva e ideal do Homem, etc., evita a cristalização num dispositivo didático e de controle, aceita a tarefa de criar e recriar a todo instante "o trabalho constante da produção de outros modos de vida, de novas práticas em saúde" ${ }^{\prime 23}$.

Para Rolnik ${ }^{24}$, o que o professor visa com o ensino é autorizar e suscitar no aluno o "aprendiz/criador", que não será igual a sua pessoa, não falará as mesmas coisas, nem com o mesmo estilo, já que o que se produz nessa posição é singular. Para a autora, para suscitar esse aprendiz/criador no aluno, o professor tem que estar podendo suscitá-lo em si mesmo. Para isso, depende dele ir sempre se desfazendo da condição de escravo de um eu, para ir conquistando a possibilidade de se deixar conduzir, deixar-se estranhar e embarcar no devir.

\section{CONSIDERAÇÕES FINAIS}

A via escolhida para este estudo, não é a única possível e não houve a intenção de esgotar o assunto, sendo importante que surjam outras formas de estudar o processo de idealização da Terapia Ocupacional pelos alunos e como se dá a efetivação desta em ações, que resultem em transformações das realidades da população atendida. Este trabalho parte de uma situação especifica, em um curso novo, em um local onde a Terapia Ocupacional é pouco conhecida, no entanto, a discussão apresentada parece pertinente à construção do processo de formação da profissão.

A idealização da Terapia Ocupacional, a forma como será construída no processo de formação parece ser determinante da qualidade das ações na realidade dos atendimentos. Estar aberto ao inédito, ao novo, ao imanente das relações não se aprende apenas no contato com a população atendida, mas, como discutido, se vivencia desde a relação professor-aluno, em um processo que não só se inclui a diferença, mas também a potencializa.

Para além da cisão entre o ideal e o real, a proposta é pensar a questão do processo de formação como um espaço aberto, multivetorial, que possa produzir diferenciações, experimentações, afirmar modos de existência singular. É na relação professoraluno, terapeuta ocupacional-população atendida, que se reproduz a liberdade de olhar um contexto sem ter a obrigação de ter seu sentido esgotado. É poder escutar, acolher a processualidade para que outros modos de existência estejam sempre se efetivando. 


\section{REFERÊNCIAS}

1. Berenstein I, Puget J. O vínculo e o outro. Rev Bras Psicanal. 2000;35(2).

2, Bettoi W, Simao LM. Profissionais para si ou para outros? Algumas reflexões sobre a formação dos psicólogos. Psicol Cienc Prof, Brasília. 2000;20(2):20-31. http://dx.doi.org/10.1590/ S1414-98932000000200005

3. Lima EMPA. Identidade e complexidade: composições no campo da terapia ocupacional. Rev Ter Ocup Univ São Paulo, São Paulo. 1999;10(2/3):42-6.

4. Tedesco S, Liberman F. O que fazemos quando falamos em vulnerabilidade? Mundo Saude, São Paulo. 2008;32(2). Disponível em: http://www.saocamilo-sp.br/pdf/mundo_ saude/59/254a260.pdf

5. Constantinidis TC, Marinho FD. Ser ou não ser T.O.: aspirações profissionais de alunos ingressantes em curso de Terapia Ocupacional. In: XII Congresso Brasileiro e Latino Americano de Terapia Ocupacional, 2011, São Paulo. Cad Ter Ocup UFSCar, São Carlos. 2011;19.

6. Marinho FD, Constantinidis TC, Neves ATL, Gomes CMS, Vedove LM. Terapia ocupacional e integralidade na visão de alunos de cursos da saúde da Universidade Federal do Espírito Santo. In: XII Congresso Brasileiro e Latino Americano de Terapia Ocupacional, 2011, São Paulo. Cad Ter Ocup UFSCar, São Carlos. 2011;19.

7. Baccaro TA, Shinyashiki GT. Vocational choice consistency and the professional socialization of nursing students. Rev Bras Orientac Prof, São Paulo. 2011;12(1):73-82. Disponível em: http://www.redalyc.org/pdf/2030/203018660009.pdf

8. Ramos, M. Práxis e pragmatismo: referências contrapostas dos saberes profissionais. In: Sá MRGB, Fartes VLB, organizadores. Currículo, formação e saberes profissionais: a (re) valorização epistemológica da experiência. Salvador: EDFBA; 2010. p.85106. Disponível em: https://repositorio.ufba.br/ri/bitstream/ ri/1046/1/Curriculo,forma $\% C 3 \% A 7 \mathrm{ao} \% 20 \mathrm{e} \% 20$ saberes.pdf

9. Brasil. Ministério da Saúde. Secretaria de Atenção Básica. Departamento de Atenção Básica. Política nacional de atenção básica. 4a. ed. Brasília, DF; 2007. Disponível em: http://189.28.128.100/dab/docs/publicacoes/pactos/pactos vol4.pdf

10. Mitre SMM. O desafio de transformar o projeto pedagógico do curso de Terapia Ocupacional da FAMINAS-BH: equidade, qualidade e interdisciplinaridade. In: XII Encontro Nacional de Docentes de Terapia Ocupacional, II Seminário Nacional de Pesquisa em Terapia Ocupacional. Anais. Cad Ter Ocup UFSCar, São Carlos. 2012;20(supl. esp.).

11. Nicolau SM, Cid MFB, Silva CR, Barba PCSD, Goncalves FP, Souza F, Patti LP, Pinheiro MA, Garcia PE, Silva VFE.
O projeto pedagógico do curso de graduação em Terapia Ocupacional da UFSCar: avanços e desafios. In: XII Encontro Nacional de Docentes de Terapia Ocupacional, II Seminário Nacional de Pesquisa em Terapia Ocupacional. Anais. Cad Ter Ocup UFSCar, São Carlos. 2012;20(supl. esp.).

12. Pinto MPP, Elui VMC, Kebbe LM, Carreta RYD, Peres CM. Reestruturação curricular: a experiência do curso de Terapia Ocupacional da FMRP-USP. In: XII Encontro Nacional de Docentes de Terapia Ocupacional, II Seminário Nacional de Pesquisa em Terapia Ocupacional. Anais. Cad Ter Ocup UFSCar, São Carlos. 2012;20(supl. esp.).

13. Vieira ACVC. Metodologias ativas como elemento articulador na implantação do currículo integrado no curso de Terapia Ocupacional, Fortaleza-CE. In: XII Encontro Nacional de Docentes de Terapia Ocupacional, II Seminário Nacional de Pesquisa em Terapia Ocupacional. Anais. Cad Ter Ocup UFSCar, São Carlos. 2012;20(supl. esp.).

14. Pimentel AM, Costa MTB, Souza FR. Terapia ocupacional na atenção básica: a construção de uma prática. Rev Ter Ocup Univ São Paulo. 2011;22(2):110-6. Disponível em: http://www. revistas.usp.br/rto/article/viewFile/14128/15946

15. Chiovatto M. O professor mediador. Boletim Arte Escola, $n$. 24. São Paulo: Instituto Arte na Escola; 2000. Disponível em: http://fvcb.com.br/site/wp-content/uploads/2012/05/Canal-doEducador_O-Professor-Mediador.pdf

16. Spinoza B. Ética. Belo Horizonte: Autentica Editora; 2007.

17. Spinoza B. Tratado político. São Paulo: Ícone; 1994.

18. Andrade AN. Práticas psicológicas, epistemicídio e unidades básicas de saúde. Rev Psicol Política. 2007;7(13).

19. Passos E. Paradigma ético, estético e político como dispositivo no processo de formação do profissional de saúde. In: XII Encontro Nacional de Docentes de Terapia Ocupacional, II Seminário Nacional de Pesquisa em Terapia Ocupacional. Anais. Cad Ter Ocup UFSCar, São Carlos. 2012;20(supl. esp.).

20. Guattari F. Psicanálise e transversalidade. Aparecida: Ideias e Letras; 2004.

21. Deleuze G. Crítica e clínica. São Paulo: Edições 34; 1997.

22. Yonezawa FH. A problematização deleuzeana do aprender e do pensar como transversalidade para um currículo educacional. Rev Difere. 2013;3(5):1-21. Disponível em: http://www. artificios.ufpa.br/Artigos/Dossi\%C3\%AA\%20Fernando.pdf

23. Benevides R, Passos E. Humanização na saúde: um novo modismo? Interface, Botucatu. 2005;9(17):389-406. Disponível em: http://www.scielo.br/pdf/icse/v9n17/v9n17a14

24. Rolnik S. Pensamento, corpo e devir Uma perspectiva ético/ estético/política no trabalho acadêmico. Cad Subjetividade, São Paulo. 1993;1(2): 241-51. 